\title{
Inibição e inativação de Escherichia coli por extratos de plantas com indicativo etnográfico medicinal ou condimentar
}

\author{
Escherichia coli inhibition and inactivation by extracts from \\ plants with medicinal and spice ethnographic indicative \\ José Maria WIEST ${ }^{1 *}$, Heloisa Helena Chaves CARVALHO², \\ Cesar Augusto Marchionatti AVANCINI², Alexandre da Rocha GONÇALVES ${ }^{2}$
}

\section{Resumo}

Determinou-se in vitro a Intensidade de Atividade de Inibição Bacteriana (IINIB) e a Intensidade de Atividade de Inativação Bacteriana (IINAB), através de Testes de Diluição e Suspensão em Sistema de Tubos Múltiplos, de diferentes extratos aquosos ou alcoólicos/hidroalcoólicos de 59 plantas com indicativo etnográfico medicinal ou condimentar acessadas na região metropolitana de Porto Alegre/RS/BR, frente à Escherichia sp. (ou E. coli ATCC no 11229 ou E. coli p.16 CPVDF - SAA/RS), em doses-desafio $\leq 10^{8}$ UFC.mL ${ }^{-1}$. Trinta plantas apresentaram alguma atividade seletiva antiescherichia coli, enquanto as restantes 29 apresentaram nenhuma atividade. Discute-se a validade da ferramenta etnográfica na prospecção de fatores de proteção antibacteriana em plantas, bem como a influência da inibição/inativação na preditividade do diagnóstico de E. coli.

Palavras-chave: atividade antibacteriana em plantas; inibição bacteriana; inativação bacteriana; atividade antiescherichia coli; etnografia de plantas medicinais.

\begin{abstract}
The in vitro Intensity of Bacterial Inhibition Activity (IINIB) and the Intensity of Bacterial Inactivation Activity (IINAB) of diverse aqueous alcoholic/hydroalcoholic from extracts of 59 plants with medicinal or spice ethnographic indicative assessed in Porto Alegre/RS/BR, were determinated against Escherichia sp. (or E. coli ATCC no 11229 or E. coli p.16 CPVDF - SAA/RS) in challenge doses $\leq 10^{8} \mathrm{CFU}^{\mathrm{m}} \mathrm{mL}^{-1}$. Extracts of 30 plants presented some anti-Escherichia coli selective activity while the remaining 29 plants presented no activity. The validity of ethnographical search instruments in the prospection of anti-bacterial protection factors in plants and the influence of inhibition/inactivation results in the prediction of $E$. coli diagnostic were discussed.

Keywords: plants' antibacterial activity; bacterial inhibition; bacterial inactivation; anti-Escherichia coli activity; medicinal plants ethnography.
\end{abstract}

\section{Introdução}

A Escherichia coli encontra-se largamente difundida na natureza, tendo como habitat principal o trato intestinal de animais de sangue quente, integrando as bactérias do grupo coliforme, subdividindo-se em vários biótipos e sorotipos, alguns dos quais patogênicos em potencial para o homem constituindo-se os alimentos e a água suas principais fontes de infecção. A bactéria é referenciada ainda hoje como indicador de contaminação fecal, mormente em alimentos, pela facilidade de sua comprovação diagnóstica e por sua representatividade (FRAZIER; WESTHOFF, 1993). Os diferentes sorotipos (enterohemorrágico, enterotoxígeno, enteroinvasor, enteropatógeno e enteroagregativo) de E. coli vêm merecendo crescente atenção epidemiológica, tendo-se em conta os riscos para os humanos expostos à esta zoonose considerada emergente (ACHA; SZYFRES, 2003).

Na epidemiologia e profilaxia de doenças transmissíveis, a pesquisa de fatores de proteção sustentáveis, mormente entre recursos naturais renováveis como plantas com indicativo medicinal, condimentar ou aromático, constitui prioridade segundo a orientação da Organização Mundial da Saúde, Conferências Mundiais de Saúde, com ênfase em aspectos culturais tradicionais envolvidos e sua relação com a atenção básica em saúde (AKERELE, 1993, 1988; ORGANIZACIÓN PANAMERICANA DE LA SALUD, 1984, 1985, 1990).

O Grupo de Pesquisa "Alimentos de Origem Animal" do Diretório dos Grupos de Pesquisa do $\mathrm{CNPq} / \mathrm{MCT} /$ Brasil vem dedicando-se, entre outros objetivos, à prospecção de atividade antibacteriana em extratos de plantas com indicativo etnográfico medicinal, condimentar ou aromático expressa em Intensidade de Atividade de Inibição Bacteriana (IINIB) e de Intensidade de Atividade de Inativação Bacteriana (IINAB), apresentando-se neste trabalho a síntese dos resultados relativos à Escherichia coli. Discute-se, outrossim, a probabilidade de interveniência da inibição/inativação constatada na preditividade do diagnóstico

Recebido para publicação em 13/6/2007

Aceito para publicação em 16/5/2009 (002601)

${ }^{1}$ Departamento de Ciência dos Alimentos, Laboratório de Higiene, Instituto de Ciência e Tecnologia de Alimentos, Universidade Federal do Rio Grande do Sul - UFRGS,

CP 15090, CEP 91501-970, Porto Alegre - RS, Brasil, E-mail: jmwiest@ufrgs.br

${ }^{2}$ Programa de Pós-graduação em Ciências Veterinárias, Universidade Federal do Rio Grande do Sul - UFRGS

${ }^{*}$ A quem a correspondência deve ser enviada 
desta bactéria, bem como a validação da ferramenta etnográfica na prospecção de recursos em saúde.

\section{Material e métodos}

Foram testadas duas amostras de Escherichia coli, uma delas padrão American Type Culture Collection (ATCC, 1229) e outra, a amostra E. coli "p. 16", isolada de campo, cedida pelo Laboratório de Patologia Animal/Laboratório de Bacteriologia do Centro de Pesquisas Veterinárias Desidério Finamor/ Secretaria da Agricultura e do Abastecimento do Estado do Rio Grande do Sul. As amostras foram mantidas em bacterioteca, ativadas em meio BHI (Brain Hearth Infusion - DIFCO ${ }^{\circledR}$ ) a $37^{\circ} \mathrm{C}$ em aerobiose, atingindo os inóculos no mínimo $\geq 10^{8}$ UFC. $\mathrm{mL}^{-1}$, entre 18 e 24 horas.

Através do método qualitativo de etnografia rápida (ETKIN, 1993), fez-se o resgate de saberes e fazeres tradicionais relacionados às 59 plantas, com a participação de 16 diferentes informantes (remanescentes quilombolas, ameríndios e de imigrantes teutos, de curadores tradicionais e de voluntários da Pastoral da Saúde), registrando-se seu Consentimento Livre e Esclarecido segundo Clotet et al. (2000), como orienta o Decreto $\mathrm{n}^{\circ} 4.339$ da Política Nacional de Biodiversidade, Diretriz no 2 (XII), de 22 de agosto de 2002.

Todas as plantas foram acessadas na região metropolitana de Porto Alegre, RS, Brasil, identificadas botanicamente e encaminhadas como excicatas segundo Ming (1996) para registro no Herbário do Departamento de Botânica do Instituto de Ciências Biológicas da UFRGS.

Os diferentes acessos foram utilizados imediatamente pós-colheita, ainda verdes, ou secos à sombra sob ventilação e assim armazenados para uso posterior. Os diferentes extratos vegetais, no princípio de droga crua, foram obtidos segundo Farmacopéia (1959), ocorrendo ou não a reposição/reidratação posterior, constituindo-se de decoctos (plantas verdes ou secas), de alcoolaturas (plantas verdes) ou de hidroalcoolaturas (plantas secas); as duas últimas submetidas à destilação fracionada sob pressão reduzida em aparelho de rota-vapor.

Para a avaliação da intensidade da atividade antibacteriana dos diferentes extratos estudados, lida como IINIB e IINAB, utilizaram-se os Testes de Diluição e de Suspensão (DEUTSCHE VETERINÄRMEDIZINISCHE GESELLSCHAFT/DVG, 1981), com base na Técnica do Sistema de Tubos Múltiplos, modificada por Avancini (2000), confrontando os diferentes extratos vegetais com oito diluições seriais logarítmicas $\left(10^{-1}\right.$ a $10^{-8}$ ou mesmo $10^{-9}$ UFC. $\mathrm{mL}^{-1}$ ) das diferentes E. coli em teste, controlando por plaqueamento o crescimento bacteriano específico, bem como contaminações intervenientes. Entendeu-se por IINIB o resultado do confronto de $E$. coli com o extrato vegetal em meio específico e IINAB o mesmo resultado, porém sob influência dos desinibidores bacterianos (DVG, 1981). Os resultados de IINIB e de IINAB foram representados por variáveis ordinais arbitrárias, que assumiram valores de 8 (oito) ou mesmo 9 (nove) a 0 (zero), indicando a intensidade destas atividades e de suas correspondentes diluições/doses infectantes dos inóculos de E. coli. Desta maneira, atribuiu-se o valor máximo 8, ou mesmo 9, quando a atividade de inibição ou de inativação de uma determinada concentração do extrato vegetal correspondeu a $10^{-1}$ ou a $10^{7}$ ou $10^{8}$ U.F.C.mL ${ }^{-1}$ (partindo-se de uma cultura ativada com no mínimo $10^{8}$ ou mesmo $10^{9} \mathrm{UFC} \cdot \mathrm{mL}^{-1}$ ), ou valor zero quando da verificação de nenhuma atividade, tanto de inibição como de inativação, demonstrada pela concentração do extrato vegetal em teste.

Em todos os testes avaliaram-se os resultados de IINIB e de IINAB através de análise estatística descritiva e análise de variância, com complementação pelo Teste de Duncan e Teste t de Student.

\section{Resultados e discussão}

Entre 59 plantas com indicativo etnográfico medicinal, condimentar ou aromático (ARAUJO, 2007; AVANCINI, 1995, 2000, 2002; BEDIN, 1998; CARVALHO, 2004, 2005; GIROLOMETTO, 2005; GONÇALVES, 2005; GUTKOSKI, 1999; MOTTA, 2007; SOUTO, 2006; SOUZA, 1998, 2000, 2005) acessadas na região metropolitana de Porto Alegre, Rio Grande do Sul, Brasil, 30 apresentaram alguma atividade antiescherichia coli, (Tabela 1), enquanto as outras 29 apresentaram nenhuma atividade (Tabela 2), embora tenham apresentado complexo referencial etnográfico de uso em agravos à saúde envolvendo agentes infecciosos, ferimentos/cicatrização, manifestações gastrintestinais, conservação de alimentos, promoção e proteção da saúde humana e da saúde e produção animal.

Dentre as plantas acessadas, nas condições dos diferentes experimentos, por atingirem valores arbitrários atribuídos em grau máximo em IINIB ou em IINAB, destacam-se como condimentares: "salvia" (Salvia officinalis) (CARVALHO, 2004, 2005), "pimentamalagueta” (Capsicum frutescens) (CARVALHO, 2004, 2005), "alho-porro" (Allium porrum) (CARVALHO, 2004, 2005), "alho-nirá" ou "jiucai" (Allium tuberosum) (ARAUJO, 2007; CARVALHO, 2004, 2005), "manjerona-branca” (Origanum applii) (BEDIN, 1998; CARVALHO, 2004, 2005) e "manjericão" (Ocimum basilicum) (SOUTO, 2006); entre as plantas com indicativo somente medicinal encontram-se: "folha-da-fortuna" (Bryophillum pinnatum) (GONÇALVES, 2005), "bardana" (Arctium minus) (GONÇALVES, 2005), "ramas de batata-doce" (Ipomoea batatas) (GONÇALVES, 2005), "erva-de-formigueiro" (Chenopodium álbum) (GONÇALVES, 2005), "erva-deSão-Simão" ou "erva-de-preta-velha" (Vernonia scorpioides) (GONÇALVES, 2005), sete-sangrias (Cuphea carthagenensis) (GONÇALVES, 2005), "chapéu de couro"(Sagittaria montevidensis) (GONÇALVES, 2005), "macela” (Achyroclines satureoides) (AVANCINI et al., 2000; MOTTA, 2007), "baleeira" (Cordia curassavica) (GONÇALVES, 2005), "carqueja" (Baccharis trimera) (AVANCINI, 1995, 2000) e "chinchilho" (Tagetes minuta) (SOUZA, 1998, 2000).

Especificamente dentre as plantas com indicativo condimentar destacam-se "pimenta-malagueta" (Capsicum frutescens) (CARVALHO, 2004, 2005) e "manjericão" (Ocimum basilicum) (SOUTO, 2006) por apresentarem inibição grau máximo (bacteriostasia), porém inativação grau mínimo (bactericidia), constituindo esta constatação fator de risco, relativo à obtenção de resultados de pesquisa diagnóstica falso-negativos do microorganismo em questão, em amostras de alimentos 


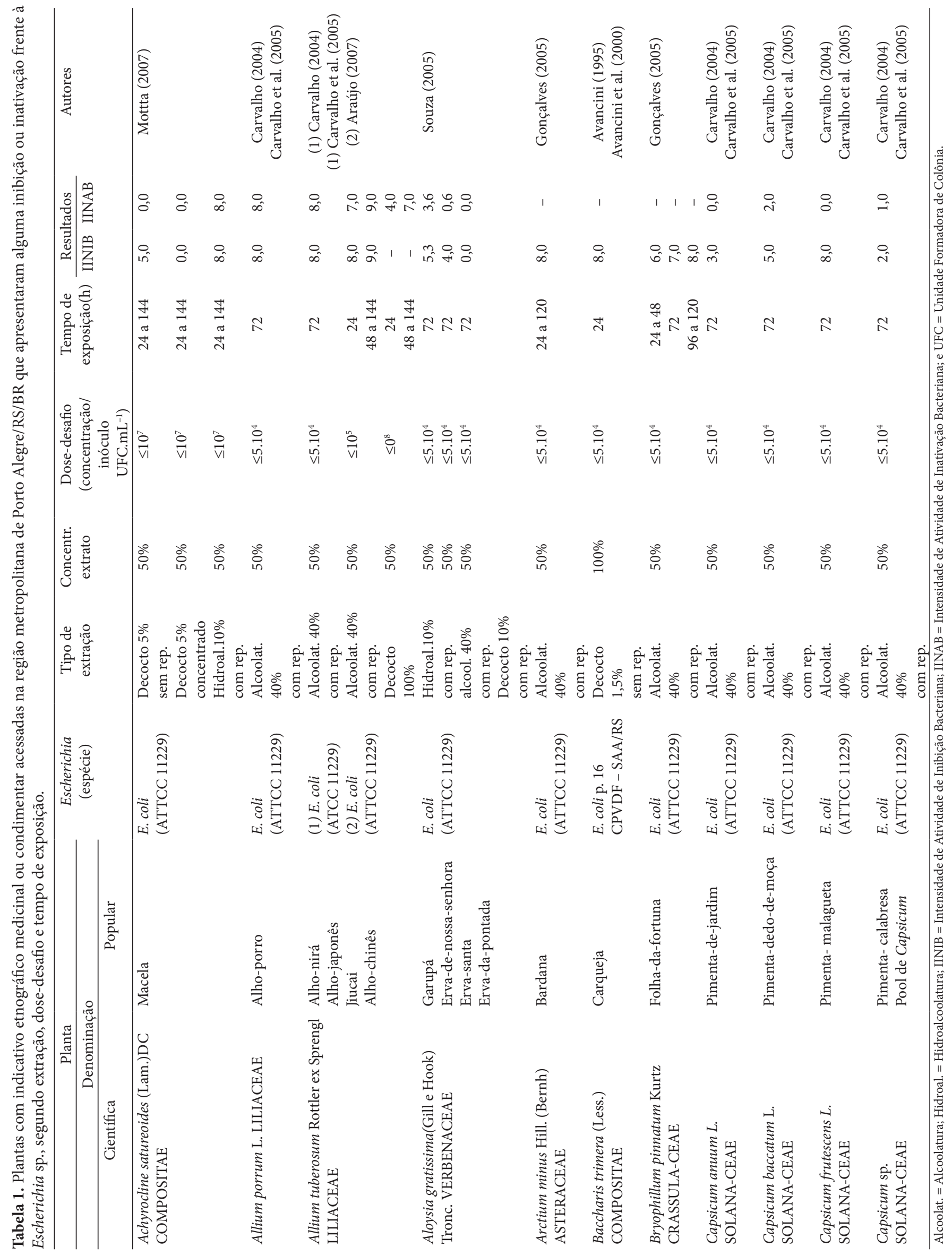




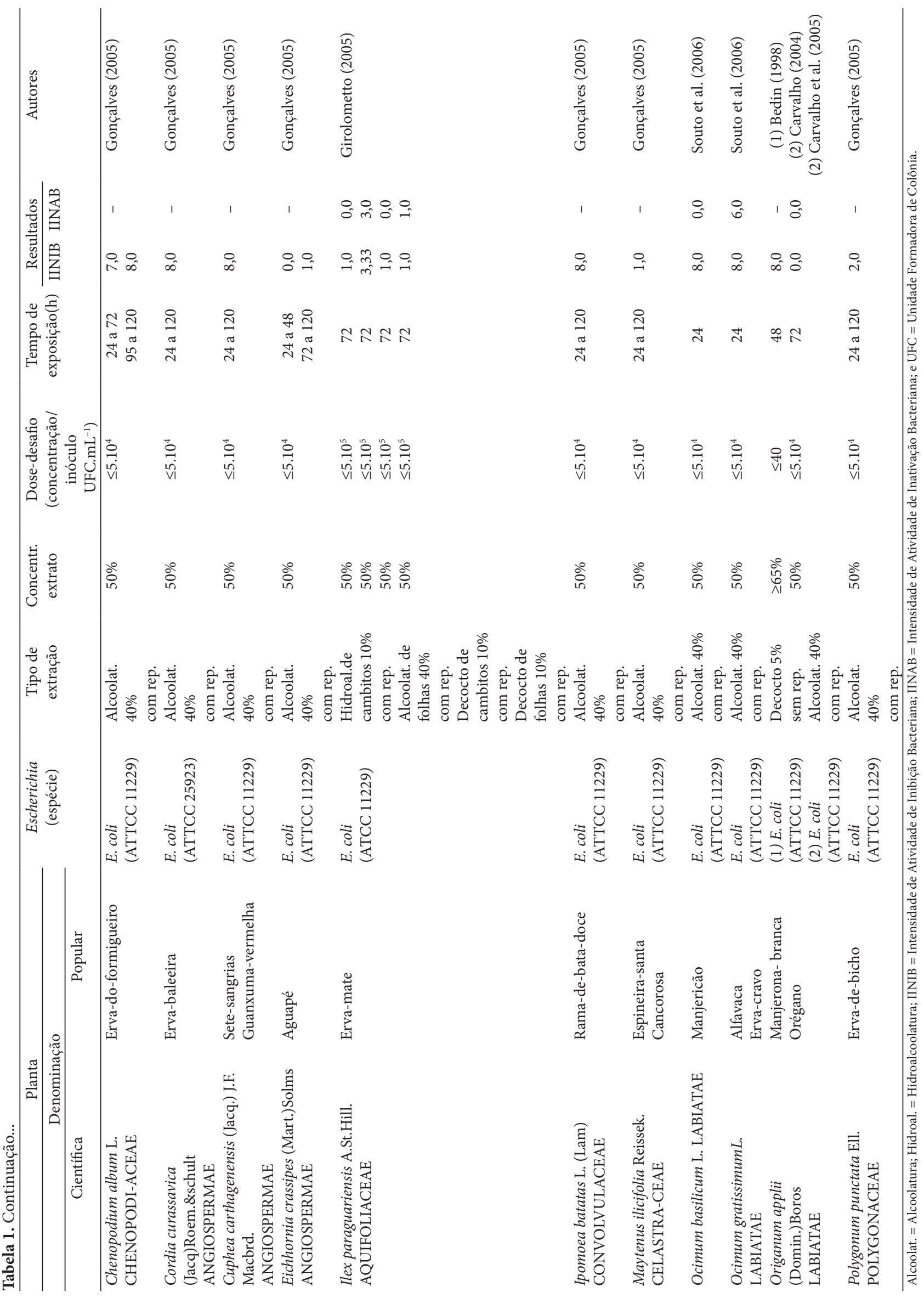


Atividade antiescherichia em plantas

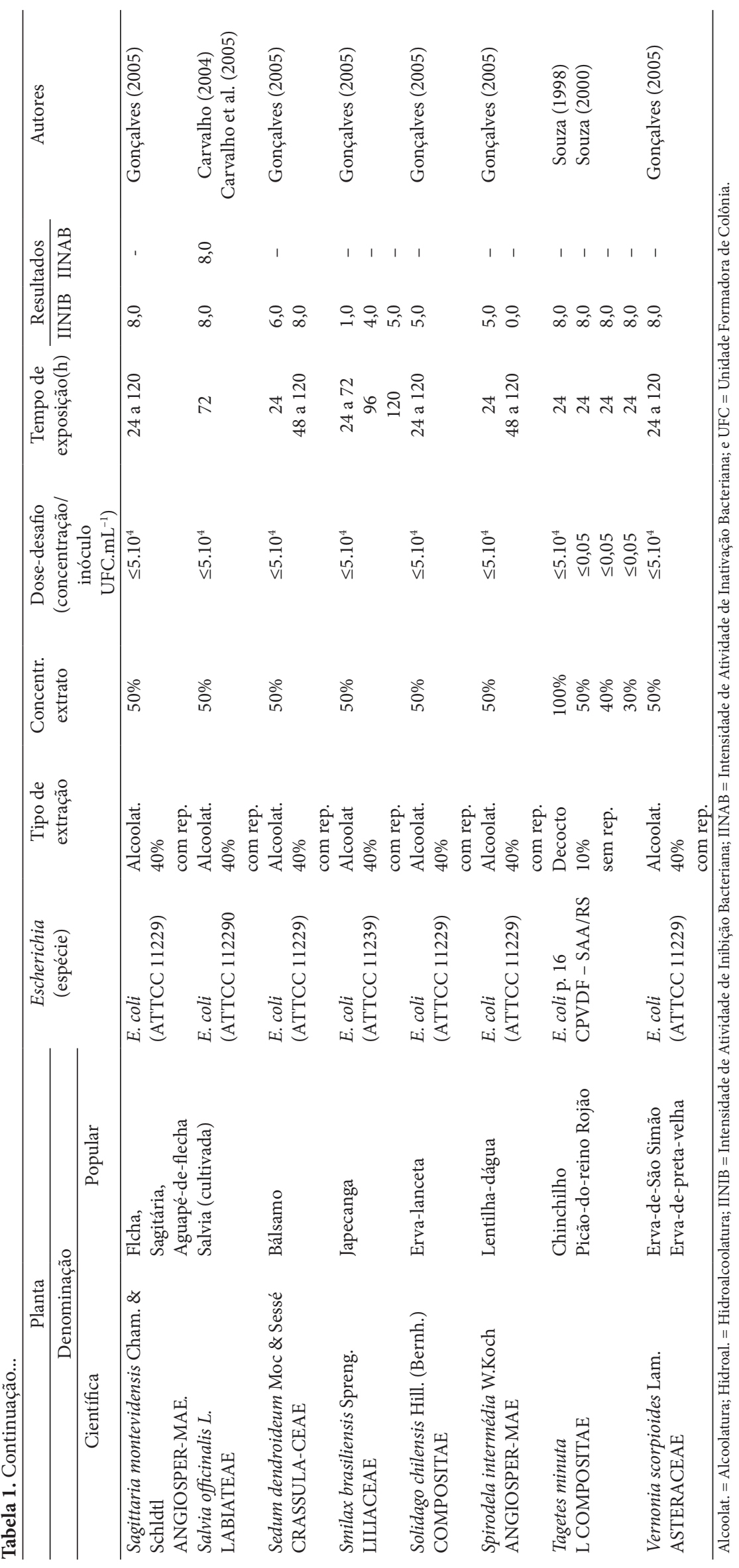


Tabela 2. Plantas com indicativo etnográfico medicinal ou condimentar acessadas na região metropolitana de Porto Alegre/RS/BR que apresentaram nenhuma inibição ou inativação frente à Escherichia sp., segundo as formas de extração estudadas.

\begin{tabular}{|c|c|c|c|}
\hline \multicolumn{2}{|l|}{ Denominação } & \multirow[t]{2}{*}{ Forma de extração } & \multirow[t]{2}{*}{ Autor (ES) } \\
\hline Científica & Popular & & \\
\hline Allium fistulosum L. LILIACEAE & Cebola-todo-ano & Alcoolatura $40 \%$ com reposição & Carvalho (2004) \\
\hline Allium sativum L. LILIACEAE & Alho-macho & Hicroalcoolatura $10 \%$ com reposição & Carvalho (2004) \\
\hline Anethum graveolens L. UMBELLIFERAE & Endro & Alcoolatura $40 \%$ com reposição & Carvalho (2004) \\
\hline Artemisia dracunculus L. var. inodora ASTERACEAE & Estragão & Alcoolatura $40 \%$ com reposição & Carvalho (2004) \\
\hline Capsicum annuum L. SOLANACEAE & Pimentão vermelho & Alcoolatura $40 \%$ com reposição & Carvalho (2004) \\
\hline Capsicum baccatum L. SOLANACEAE & Pimenta cambuci & Alcoolatura $40 \%$ com reposição & Carvalho (2004) \\
\hline Casearia sylvestris Swartz FLACOURTIACEAE & Guaçatonga Chá-de-bugre & Decocto $5 \%$ sem reposição & Gutkoski (1999) \\
\hline Conyza bonariensiss L. Cronquist COMPOSITAE & Erva carniceira & Alcoolatura $40 \%$ com reposição & Gonçalves (2005) \\
\hline Coriandrum sativum L. UMBELLIFERAE & Coentro & Alcoolatura $40 \%$ com reposição & Carvalho (2004) \\
\hline Melissa officinalis L. LABIATAE & Melissa & Alcoolatura $40 \%$ com reposição & Carvalho (2004) \\
\hline Ociumum selloi Benth LABIATAE & Anis-verde & Alcoolatura $40 \%$ com reposição & Souto et al. (2006) \\
\hline Origanum majorana L. LABIATAE & Manjerona-preta & Alcoolatura $40 \%$ com reposição & Carvalho (2004) \\
\hline Petroselinum sativum H. UMBELIFERAE & Salsa-verde & Alcoolatura 40\% com reposição & Carvalho (2004) \\
\hline Petroselinum crispum H. UMBELIFERAE & Salsa-raiz & Alcoolatura $40 \%$ com reposição & Carvalho (2004) \\
\hline Piper nigrum L. PIPERACEAE & Pimenta-preta & Alcoolatura $40 \%$ com reposição & Carvalho (2004) \\
\hline Piper sp. L. PIPERACEAE & Pimenta-branca & Alcoolatura $40 \%$ com reposição & Carvalho (2004) \\
\hline Pistia stratiotes L. ANGIOSPERMAE & Alface-de-água & Alcoolatura $40 \%$ com reposição & Gonçalves (2005) \\
\hline Rosmarinus officinalis L. LABIATAE & Alecrim & Alcoolatura 40\% com reposição & Carvalho (2004) \\
\hline Thymus citriodorus L. LAMIACEAE & Tomilho-citronela & Alcoolatura $40 \%$ com reposição & Carvalho (2004) \\
\hline
\end{tabular}

condimentados com estas plantas e epidemiologicamente investigados em surtos toxinfectivos.

A triagem de agentes medicinais ativos em plantas, não obrigatoriamente antimicrobianos, permite atingir escores de $1: 10$, ou seja, $10 \%$ de plantas com alguma atividade evidenciada, entre o total de plantas pesquisadas com indicativo etnográfico de uso medicinal tradicional (MALONE, 1983). Neste sentido, Avancini (2000) alcançou percentual de acertos de 51,42\%, Carvalho $(2004,2005)$ atingiu 37,50\% e Gonçalves (2005) totalizou $88,80 \%$, enquanto no presente trabalho, dentre as 59 plantas estudadas pelo Grupo neste período, atingiu-se escore de 50,84\% de acertos específicos em relação à Escherichia coli, sinalizando a validação do resgate etnográfico como ferramenta na prospecção de plantas medicinais como fatores de proteção antibacteriana, a partir de saberes tradicionais compartilhados.

As técnicas de Diluição e de Suspensão através de Sistema de Tubos Múltiplos demonstraram, outrossim, acuidade, ao se reproduzirem resultados com diferentes acessos de determinadas plantas, mesmo após o intervalo de alguns anos, no exemplo de "alho-nirá" (Allium tuberosum), (ARAUJO, 2007; CARVALHO, 2004, 2005).
Analisando especificamente os resultados de "macela" (Achyrocline satureoides) (AVANCINI et al., 2000; MOTTA, 2007) há evidências de que o tipo de extração influencia a eficácia antibacteriana, pela possível perda de elementos na decocção e ou na pré-secagem da planta antes da hidroalcoolatura, o que parece não ocorrer na técnica de extração por alcoolatura.

\section{Conclusões}

- Os escores de acerto/erro obtidos sinalizam a validação do resgate etnográfico como ferramenta na prospecção de plantas medicinais como fatores de proteção antibacteriana a partir de saberes tradicionais compartilhados.

- Determinadas plantas medicinais ou condimentares podem influir na preditividade dos resultados negativosverdadeiros/falsos-negativos de pesquisa diagnóstica de $E$. coli pela atividade de inibição/bacteriostasia demonstrada.

- As Técnicas de Diluição e de Suspensão através de Sistema de Tubos Múltiplos demonstraram acuidade ao se reproduzirem resultados com diferentes acessos da mesma planta após intervalo de tempo prolongado. 
- Há evidências de que o tipo de extração influencia a eficácia antibacteriana das soluções, prevalecendo a da alcoolatura sobre a hidroalcoolatura e os decoctos, no trabalho com droga crua.

\section{Agradecimentos}

Aos informantes, pela partilha do conhecimento tradicional. Ao CNPq, pelo estímulo e financiamento contínuos. À FAPERGS, pelo financiamento do projeto.

\section{Referências Bibliográficas}

ACHA, P. N.; SZYFRES, B. Zoonosis and communicable diseases common to men and animals: bacteriosis and mycosis. 3 ed. Washington: World Health Organization, 2003. 398 p. (Cientifical and Technical Publication, n. 580)

AKERELE, O. Las plantas medicinales: un tesoro que no debemos desperdiciar. Foro Mundial de la Salud, v. 14, p. 390-395, 1993.

AKERELE, O. Medicinal plants and primary health care: a agend for action. Fitoterapia, v. LIX, n. 5, p. 355-363, 1988.

ARAUJO, C. D. Atividade antibacteriana in vitro e in sito de Allium tuberosum - Rottler ex Spengl (alho "nirá", alho "japonês", "jiucai", alho "chinês") - Liliaceae - sobre agentes de toxiinfecções alimentares. 2007. 85 f. Dissertação (Mestrado em Ciência Veterinária) - Faculdade de Veterinária, Universidade Federal do Rio Grande do Sul, Porto Alegre.

AVANCINI, C. A. M. Desinfecção em saúde e produção animal: bacteriostasia e bactericidia de Baccharis trimera (Less.) D.C. Compositae - ("carqueja") frente a microorganismos entéricos e cutâneos. 1995. 152 f. Dissertação (Mestrado em Ciência Veterinária) - Faculdade de Veterinária, Universidade Federal do Rio Grande do Sul, Porto Alegre.

AVANCINI, C. A. M. Saneamento aplicado em saúde e produção animal: etnografia, triagem da atividade antibacteriana de plantas nativas no sul do Brasil e testes de avaliação do decocto de Hypericum caprifoliatum Cham. e Schlecht. - Hypericaceae (Guttiferae) - ("escadinha", "sinapismo") para uso como desinfetante e antisséptico. 2002. 309 f. Tese (Doutorado em Ciência Veterinária) - Faculdade de Veterinária, Universidade Federal do Rio Grande do Sul, Porto Alegre.

AVANCINI, C. A. M.; WIEST, J. M.; MUNDSTOCK, E. Atividade bacteriostática e bactericida do decocto de Baccharis trimera (Less.) D.C., Compositae - carqueja - como desinfetante ou anti-séptico. Arquivo Brasileiro de Medicina Veterinária e Zootecnia, v. 52, n. 3, p. 230-234, 2000.

$\mathrm{BEDIN}, \mathrm{C}$. Atividade antibacteriana in vitro do decocto de Origanum applii (Domin.) Boros - Labiatae (“orégano", “manjerona”) sobre agentes de interesse em alimentos. 1998. $90 \mathrm{f}$. Dissertação (Mestrado em Ciência Veterinária) - Faculdade de Veterinária, Universidade Federal do Rio Grande do Sul, Porto Alegre.

CARVALHO, H. H. C. Avaliação da atividade antibacteriana de plantas com indicativo etnográfico condimentar. 2004. $200 \mathrm{f}$. Tese (Doutorado em Ciência Veterinária) - Faculdade de Veterinária, Universidade Federal do Rio Grande do Sul, Porto Alegre.

CARVAlHO, H. H. C.; CRUZ, F. T.; WIEST, J. M. Atividade antibacteriana em plantas com indicativo etnográfico condimentar em Porto Alegre, RS / Brasil. Revista Brasileira de Plantas Medicinais, v. 7, n. 3, p. 25-32, 2005.

CLOTET, J.; GOLDIM, J. R.; FRANCISCONI, C. F. Consentimento Informado. Porto alegre: PUC-RS, 2000. $130 \mathrm{p}$.

DVG (DEUTSCHE VETERINÄRMEDIZINISCHE GESELLSCHAFT). Richtlinien zur Prüfung chemischer Desinfektionsmittel für die Veterinärmedizin. In: SCHLIESSER, T.; STRAUCH, D. Desinfektion in Tierhaltung, Fleisch- und Milchwirtschaft. Stuttgart: Enke, 1981. 455 p.
ETKIN, N. L. Anthropological methods in ethnopharmacology. Journal of Ethnopharmacology, v. 38, n. 2, p. 93-104, 1993.

FARMACOPÉIA dos Estados Unidos do Brasil. 2 ed. São Paulo: Siqueira, 1959. $532 \mathrm{p}$.

FRAZIER, W. C.; WESTHOFF, D. C. Microbiologia de los alimentos. Zaragoza: Acribia, 1993. 681 p.

GIROLOMETTO, G. Avaliação da atividade antibacteriana de estratos de Ilex paraguaiensis A. ST. Hill. - Aquifoliaceae ("erva-mate") frente a bactérias zoonóticas em saúde e produção animal. 2005. 71 f. Dissertação (Mestrado em Ciência Veterinária) Faculdade de Veterinária, Universidade Federal do Rio Grande do Sul, Porto Alegre.

GONÇALVES, A. da R. Fitodesinfecção aplicada à água na perspectiva da agricultura e da agroindústria familiar. 2005. $130 \mathrm{f}$. Tese (Doutorado em Ciência Veterinária) - Faculdade de Veterinária, Universidade Federal do Rio Grande do Sul, Porto Alegre.

GUTKOSKI, S. Atividade antibacteriana in vitro do decocto de Casearia sylvestris, Swartz - Flacourtiaceae - ("chá-de- bugre", "guaçatonga") sobre agentes de interesse em saúde animal e saúde coletiva. 1999. 84 f. Dissertação (Mestrado em Ciência Veterinária) - Faculdade de Veterinária, Universidade Federal do Rio Grande do Sul, Porto Alegre.

MALONE, M. H. The pharmacological evaluation of natural products: general and specific approaches to screening ethnopharmaceuticals. Journal of Ethnopharmacology, v. 8, n. 3, p. 127-147, 1983.

MING, L. C. Coleta de plantas medicinais. In: DI STASI, L. C. Plantas medicinais arte e ciência: um guia de estudo interdisciplinar. São Paulo: UNESP, 1996. p. 69-86.

MOTTA, F. M. Inibição e inativação in vitro por diferentes extratos de Achyrocline satureoides (Lamm.) DC - "macela" - Compositae sobre bactérias zoonóticas transmissíveis por alimentos. 2007. 87 f. Dissertação (Mestrado em Ciência Veterinária) - Faculdade de Veterinária, Universidade Federal do Rio Grande do Sul, Porto Alegre.

ORGANIZACIÓN PANAMERICANA DE LA SALUD - O. P. S. Cultura medica tradicional. Boletin de la Oficina Sanitária Panamericana, v. 96, n. 2, p. 180-181, 1984.

ORGANIZACIÓN PANAMERICANA DE LA SALUD - O. P. S. Cultura medica tradicional. Boletin de la Oficina Sanitária Panamericana, v. 98, n. 4, p. 373-377, 1985.

ORGANIZACIÓN PANAMERICANA DE LA SALUD - O. P. S. Cultura medica tradicional. Boletin de la Oficina Sanitária Panamericana, v. 108, n. 1, p. 77-80, 1990.

SOUTO, S. A. et al. Atividde antibacteriana in vitro de plantas condimentares do gênero Ocimum - Labiatae (O.selloi Benth. - anis verde; O. basilicum L. - manjericão; O. gratissimum L. - erva-cravo, alfavaca), frente a zoonoses transmissíveis por alimentos. In: SALÃO DE INICIAÇÃO CIENTÍFICA DA UNIVERSIDADE FEDERAL DO RIO GRANDE DO SUL, 18, Porto Alegre. Livro de Resumos... Porto Alegre: Editora da Universidade, 2006. v. 1, p. 185.

SOUZA, A. A. de. Aspectos etnobiológicos e avaliação da atividade antibacteriana de Aloysia gratissima (Gill et Hook) Tronc. Verbenaceae ("garupá", “erva santa") sobre agentes de importância em saúde e produção animal. 2005. 87 f. Dissertação (Mestrado Ciência Veterinária) - Faculdade de Veterinária Universidade Federal do Rio Grande do Sul, Porto Alegre.

SOUZA, C. A. S. de. Aspectos etnobiológicos e atividade antibacteriana in vitro de Tagetes minuta L. Compositae chinchilho. 1998. 119 f. Dissertação (Mestrado em Ciência Veterinária) - Faculdade de Veterinária, Universidade Federal do Rio Grande do Sul, Porto Alegre.

SOUZA, C. A. S.; AVANCINI, C. A. M.; WIEST, J. M. Atividade antimicrobiana de Tagetes minuta L., Compositae (chinchilho) frente a bactérias Gram-positivas e Gram-negativas. Brazilian Journal Veterinary Research and Animal Science, v. 37, n. 6, p. 1-9, Dec. 2000. 